\title{
Preparation of Hydroxyapatite Microspheres by Interfacial Reaction in a Multiple Emulsion
}

\author{
Isao KIMURA, Tatsuro HONMA and Richard E. RIMAN*
}

Graduate School of Science and Technology, Niigata University, 8050, Ikarashi 2-no-cho, Nishi-ku, Niigata-shi 950-2181, Japan *Department of Materials Science and Engineering, Rutgers, The State University of New Jersey, 607 Taylor Road, Piscataway, NJ 08854-8065, USA

\begin{abstract}
Interfacial reaction in a multiple emulsion, was carried out with the aim of preparing hollow hydroxyapatite (HAp) microspheres. The multiple emulsion was a $\mathrm{W} / \mathrm{O} / \mathrm{W}$ emulsion, made of dipotassium hydrogen phosphate solution as an inner aqueous phase, cyclohexane as an oil phase, and calcium nitrate solution as an outer aqueous phase. The phase diagrams of $\mathrm{Ca}\left(\mathrm{NO}_{3}\right)_{2}-\mathrm{K}_{2} \mathrm{HPO}_{4}-\mathrm{H}_{2} \mathrm{O}$ system were drawn by thermodynamic computations and used to simulate the chemical process in a multiple emulsion for determining the experimental conditions. Single phase HAp was synthesized at an initial $\mathrm{pH}$ of 12.0 . HAp with a $\mathrm{Ca} / \mathrm{P}$ ratio was measured by inductively coupled plasma spectroscopy to correspond to 1.49. The product was composed of microspheres of 0.5 to 2 $\mu \mathrm{m}$ in diameter. Each microsphere was composed of acicular particles with an aspect ratio of 2.5-10 with a short axis length of about $20 \mathrm{~nm}$.

[Received August 30, 2007; Accepted September 20, 2007]
\end{abstract}

Key-words : Hydroxyapatite, Microsphere, Multiple emulsion, Interfacial reaction, Phase diagram

\section{Introduction}

Microcapsules are small containers, in which an active core material can be contained and preserved for a while and from which it can be released when users desire. In the area of pharmaceutics, they are commonly used as a drug delivery system. The wall materials of most microcapsules have been generally made of polymers. Inorganic materials can be chosen for specific purposes. Hydroxyapatite $\left(\mathrm{Ca}_{10}\left(\mathrm{PO}_{4}\right)_{6}(\mathrm{OH})_{2}, \mathrm{HAp}\right)$ is a main inorganic constituent of hard tissues in the human body such as bones and teeth. Therefore, the development of microcapsules with a HAp wall is being investigated. They are expected to be applied to injectable medicines in orthopedics, prosthodontics, and so on. To achieve it, it is necessary to establish the preparation of porous or hollow HAp microspheres.

Porous HAp microspheres have been prepared in several ways. For instance, Akazawa et al. ${ }^{1)}$ and Sunny et al. ${ }^{2)}$ have used a spray drying method. Ribeiro et al. ${ }^{3}$ have used a droplet extrusion method. Hashimoto et al. ${ }^{4}$ have used a wet chemical method. These porous HAp microspheres were stuffed inside, so that they may be used as microcarriers for the controlled release of a core material. If hollow microspheres are prepared, a higher content of the core material will be attained. The interfacial reaction is known as a method by which hollow silicate microspheres are successfully prepared. ${ }^{5)-8)}$

Figure 1 illustrates the concept of the interfacial reaction. In the preparation of hollow calcium silicate $\left(\mathrm{CaSiO}_{3}\right)$ microspheres, calcium nitrate $\left(\mathrm{Ca}\left(\mathrm{NO}_{3}\right)_{2}\right)$ solution and sodium silicate $\left(\mathrm{Na}_{2} \mathrm{SiO}_{3}\right)$ solution are used as the outer and inner aqueous phases, respectively. The mechanism for the formation of hollow microspheres is thought to be most likely as follows. Calcium ion $\left(\mathrm{Ca}^{2+}\right)$ diffuses through the oil phase to the $\mathrm{W} / \mathrm{O}$ interface. It reacts with silicate ion $\left(\mathrm{SiO}_{3}{ }^{2-}\right)$ there to produce $\mathrm{CaSiO}_{3}$. If the reaction is faster than the diffusion of $\mathrm{Ca}^{2+}, \mathrm{Ca}^{2+}$ can react as soon as being reached at the interface to produce hollow microspheres.

In this study, dipotassium hydrogen phosphate $\left(\mathrm{K}_{2} \mathrm{HPO}_{4}\right)$ was substituted for $\mathrm{Na}_{2} \mathrm{SiO}_{3}$ with the aim of producing $\mathrm{HAp}$ according to Eq. (1).

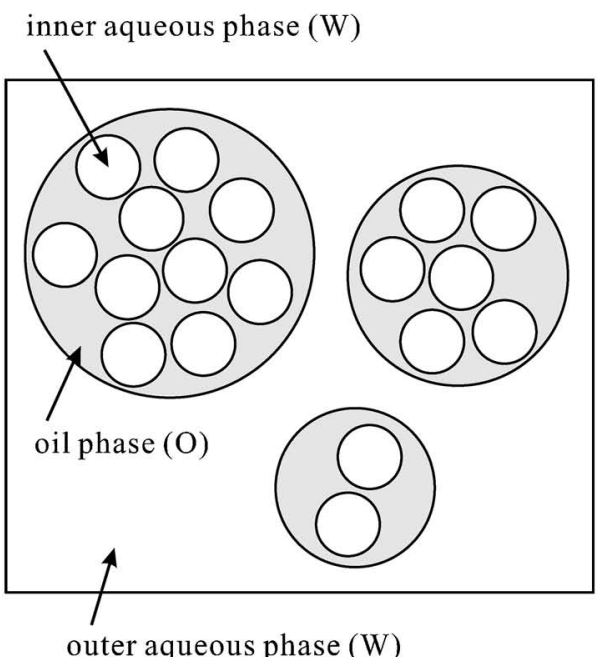

outer aqueous phase (W)

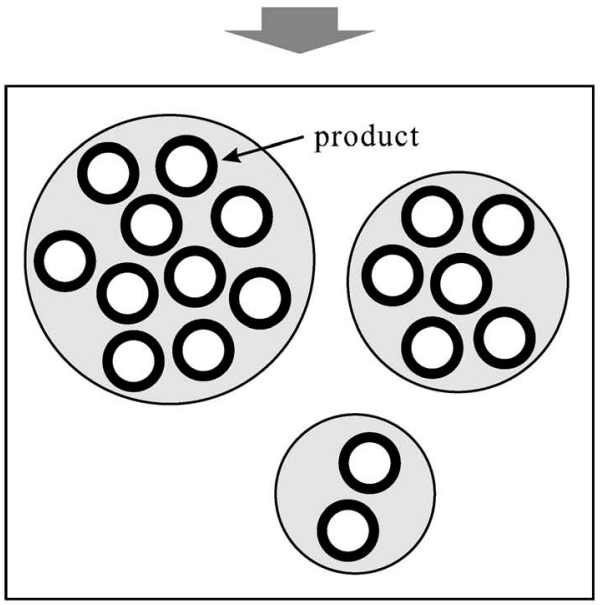

Fig. 1. Schematic diagrams of interfacial reaction in a multiple emulsion.

$$
\begin{aligned}
& 10 \mathrm{Ca}^{2+}+6 \mathrm{HPO}_{4}{ }^{2-}+2 \mathrm{OH}^{-} \\
& \stackrel{\mathrm{Ca}_{10}\left(\mathrm{PO}_{4}\right)_{6}(\mathrm{OH})_{2}+6 \mathrm{H}^{+}}{\longrightarrow}
\end{aligned}
$$


The purpose of this paper is to prove the possibility of producing HAp by the interfacial reaction and to report the characteristics of the products prepared.

The Riman research group ${ }^{9)}$-11) has used solution thermodynamics to engineer hydrothermal processes to crystallize a wide range of ceramics, including HAp. In this paper, phase equilibrium computations will be used to determine the preparation conditions that ensure production of single phase HAp in the multiple emulsion system.

\section{Thermodynamic modeling}

As described in the previous section, the reaction site in the interfacial reaction system is the $\mathrm{W} / \mathrm{O}$ interface. $\mathrm{Ca}^{2+}$ does not exist there immediately after the beginning of the preparation. It is continuously transferred to the inner aqueous droplets throughout the process. Suppose that each inner aqueous droplet is a discrete reactor, it can be regarded as a semi-batch reactor. This is a dynamic process, and hence equilibrium is not established. Since phase diagrams show the relation between phases at equilibrium, they cannot illustrate the final state in the present system. However, phase diagrams are useful in knowing the chemistry in a given system. Thus, it is believed that they are helpful to choose the experimental conditions also for the interfacial reaction with complementing information on kinetics.

The OLI Stream Analyzer, ${ }^{12)}$ which executes thermodynamic calculations based on chemical potential data, was used to draw phase diagrams. Figure 2 shows a phase diagram in the system of $\mathrm{Ca}\left(\mathrm{NO}_{3}\right)_{2}-\mathrm{K}_{2} \mathrm{HPO}_{4}-\mathrm{H}_{2} \mathrm{O}$ at a molality of $\mathrm{Ca}\left(\mathrm{NO}_{3}\right)_{2}$ of $0.5 \mathrm{~mol} \mathrm{~kg}^{-1}$ and a temperature of $323 \mathrm{~K}$ as a function of $\mathrm{pH}$ and the molality of $\mathrm{K}_{2} \mathrm{HPO}_{4}$. Potassium hydroxide $(\mathrm{KOH})$ and nitric acid $\left(\mathrm{HNO}_{3}\right)$ were used for adjusting $\mathrm{pH}$. It can be seen that no solid is produced at below $\mathrm{K}_{2} \mathrm{HPO}_{4}$ concentration of $10^{-5} \mathrm{~mol} \mathrm{~kg}^{-1}$ or at too low $\mathrm{pH}$. Dominant solid species are HAp at $\mathrm{pH}$ higher than 6 and monetite at $\mathrm{pH}$ lower than 6 .

The dotted line designates a $\mathrm{K}_{2} \mathrm{HPO}_{4}$ concentration of 0.3 mol kg${ }^{-1}$. When $\mathrm{Ca}^{2+}$ is transferred as to be $0.5 \mathrm{~mol} \mathrm{~kg}^{-1}$ in the inner aqueous phase and the equilibrium is established at a $\mathrm{pH}$ of 8 , the state will be indicated by the point $\mathrm{A}$. Then the dominant solid species is predicted to be the only HAp. Equation (1) indicates the decrease in $\mathrm{pH}$ as the reaction goes on. If the final $\mathrm{pH}$ reaches 6 at equilibrium, the state will be indicated by the point $\mathrm{B}$. This point stands in the gray area, in which $\mathrm{HAp}$ and monetite coexist. If the final $\mathrm{pH}$ reaches 4 at equilibrium, the state will be indicated by the point $\mathrm{C}$. The dominant solid species is monetite at this state. Therefore, it is concluded that $\mathrm{pH}$ of the inner aqueous phase at the beginning of the preparation should be high enough to obtain the only HAp.

Figure 3 shows a phase diagram in the system of $\mathrm{Ca}\left(\mathrm{NO}_{3}\right)_{2}-\mathrm{K}_{2} \mathrm{HPO}_{4}-\mathrm{H}_{2} \mathrm{O}$ at $323 \mathrm{~K}$ as a function of the molalities of $\mathrm{K}_{2} \mathrm{HPO}_{4}$ and $\mathrm{Ca}\left(\mathrm{NO}_{3}\right)_{2}$. The amount of $\mathrm{KOH}$ was fixed, by which the $\mathrm{pH}$ comes into 12.0 at a $\mathrm{K}_{2} \mathrm{HPO}_{4}$ concentration of $0.3 \mathrm{~mol} \mathrm{~kg}^{-1}$ and a $\mathrm{Ca}\left(\mathrm{NO}_{3}\right)_{2}$ concentration of $0.5 \mathrm{~mol} \mathrm{~kg}^{-1}$ at equilibrium. Dominant solid species are HAp and calcium hydroxide $(\mathrm{Ca}(\mathrm{OH}) 2)$ at higher and lower K2HPO4 concentrations. HAp and $\mathrm{Ca}(\mathrm{OH})_{2}$ coexist in the gray area. The dotted line designates a $\mathrm{K}_{2} \mathrm{HPO}_{4}$ concentration of $0.3 \mathrm{~mol} \mathrm{~kg}^{-1}$.

When the preparation is initiated at a $\mathrm{K}_{2} \mathrm{HPO}_{4}$ concentration of $0.3 \mathrm{~mol} \mathrm{~kg}^{-1}$, the inner aqueous phase contains $\mathrm{HPO}_{4}{ }^{2-}$ at $0.3 \mathrm{~mol} \mathrm{~kg}{ }^{-1}$ and no $\mathrm{Ca}^{2+}$. As $\mathrm{Ca}^{2+}$ diffuses to the interface, the $\mathrm{Ca}^{2+}$ concentration is increased. This situation can be illustrated by the arrow in the figure. When the $\mathrm{Ca}^{2+}$

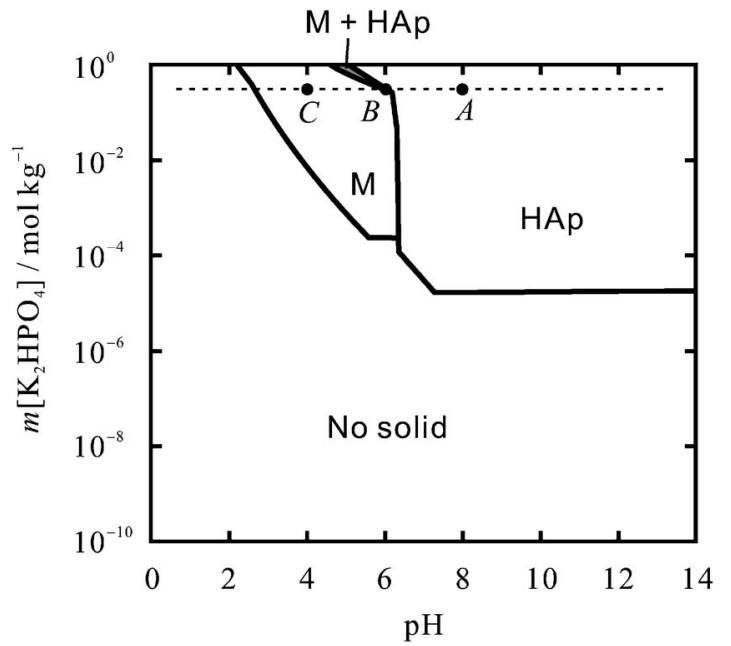

Fig. 2. Phase diagram in the system of $\mathrm{Ca}\left(\mathrm{NO}_{3}\right)_{2}-\mathrm{K}_{2} \mathrm{HPO}_{4}-\mathrm{H}_{2} \mathrm{O}$ at a molality of $\mathrm{Ca}\left(\mathrm{NO}_{3}\right)_{2}$ of $0.5 \mathrm{~mol} \mathrm{~kg}^{-1}$ and a temperature of $323 \mathrm{~K}$ as a function of $\mathrm{pH}$ and the molality of $\mathrm{K}_{2} \mathrm{HPO}_{4}$. Dominant solid species in each area is illustrated by abbreviations, HAp: hydroxyapatite and $\mathrm{M}$ : monetite.

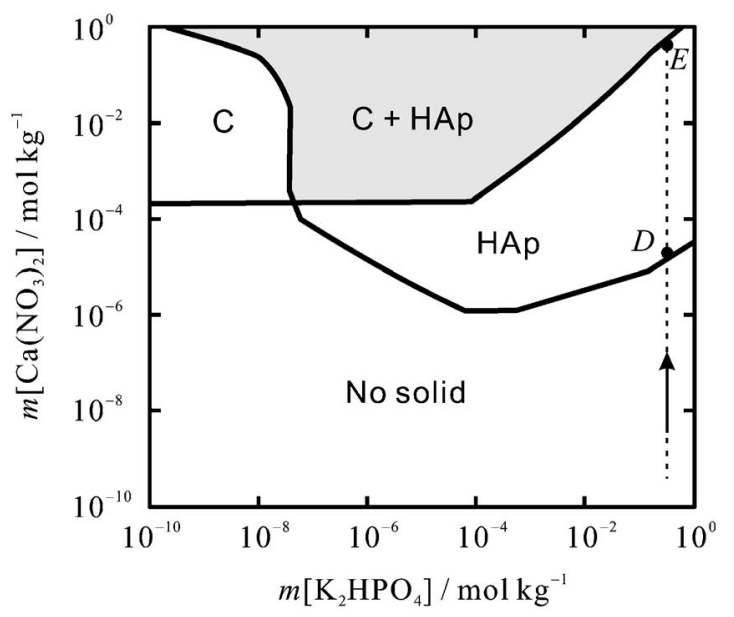

Fig. 3. Phase diagram in the system of $\mathrm{Ca}\left(\mathrm{NO}_{3}\right)_{2}-\mathrm{K}_{2} \mathrm{HPO}_{4}-\mathrm{H}_{2} \mathrm{O}$ at $323 \mathrm{~K}$ as a function of the molalitis of $\mathrm{K}_{2} \mathrm{HPO}_{4}$ and $\mathrm{Ca}\left(\mathrm{NO}_{3}\right)_{2}$. Dominant solid species in each area is illustrated by abbreviations, HAp: hydroxyapatite and $\mathrm{C}: \mathrm{Ca}(\mathrm{OH})_{2}$.

concentration goes up along this arrow and exceeds ca. $2 \times$ $10^{-5} \mathrm{~mol} \mathrm{~kg}-1$ corresponding to the point $\mathrm{D}$, HAp will start to precipitate. While $\mathrm{Ca}^{2+}$ is transferred to the inner aqueous phase and the concentration is increased up to $0.5 \mathrm{~mol} \mathrm{~kg}^{-1}$ designated by the point E, HAp is produced as dominant solid species. When the $\mathrm{Ca}^{2+}$ concentration goes beyond $0.7 \mathrm{~mol}$ $\mathrm{kg}^{-1}, \mathrm{Ca}(\mathrm{OH})_{2}$ will be produced. Therefore, $\mathrm{Ca}\left(\mathrm{NO}_{3}\right)_{2}$ concentration in the outer aqueous phase should be below this value.

From the modeling described above, the concentration of aqueous phases were determined at $0.3 \mathrm{~mol} \mathrm{~kg}^{-1}$ for $\mathrm{K}_{2} \mathrm{HPO}_{4}$ and $0.5 \mathrm{~mol} \mathrm{~kg}^{-1}$ for $\mathrm{Ca}\left(\mathrm{NO}_{3}\right)_{2}$, respectively. These concentrations are almost at a maximum in actuality. Solutions condensed more than these concentrations were so viscous that they could not be used easily in emulsion. 


\section{Experimental procedure}

The sources of HAp were $\mathrm{K}_{2} \mathrm{HPO}_{4}$ (special grade) and calcium nitrate tetrahydrate $\left(\mathrm{Ca}\left(\mathrm{NO}_{3}\right)_{2} 4 \mathrm{H}_{2} \mathrm{O}\right.$, special grade $)$. $\mathrm{KOH}$ (special grade) was used as $\mathrm{pH}$ adjuster. Two dispersion stabilizers, sorbitan monooleate (Span80, practical grade) of an oil-soluble surfactant and polyoxyethylene(20) sorbitan monolaurate (Tween20, practical grade) of a water-soluble surfactant, were used. The medium of oil phase was cyclohexane (special grade). All of the reagents were supplied from Wako Pure Chemical Industries Ltd.

An inner aqueous phase was prepared by dissolving $\mathrm{K}_{2} \mathrm{HPO}_{4}$ at $0.30 \mathrm{~mol} \mathrm{dm}^{-3}$ in deionized and distilled water, and adjusting the $\mathrm{pH}$ in the range of 9.0 to 12.0 with $\mathrm{KOH}$. Span 80 as dispersion stabilizer for the inner aqueous phase was dissolved at 5.0 mass $\%$ in cyclohexane to prepare an oil phase. $\mathrm{Ca}\left(\mathrm{NO}_{3}\right)_{2} \quad 4 \mathrm{H}_{2} \mathrm{O}$ at $0.50 \mathrm{~mol} \mathrm{dm}^{-3}$ and Tween 20 at 0.50 mass $\%$ as suspension stabilizer for the oil phase were dissolved in water to prepare an outer aqueous phase.

The preparation tank was a separable flask of $85 \mathrm{~mm}$ in inner diameter and $500 \mathrm{~cm}^{3}$ in capacity. Four baffles made of stainless steel were installed on the interior wall of the tank to inhibit the appearance of a vortex and air entrainment from the free surface of the dispersion. The inner aqueous phase of $40.5 \mathrm{~cm}^{3}$ and the oil phase of $94.5 \mathrm{~cm}^{3}$ were mixed and then agitated at $12000 \mathrm{rpm}$ for $5 \mathrm{~min}$ to prepare a W/O emulsion. This emulsion was poured into the outer aqueous phase of 315 $\mathrm{cm}^{3}$ having been stirred with a disk turbine-type impeller with six blades of $40 \mathrm{~mm}$ in diameter at $323 \mathrm{~K}$ and $300 \mathrm{rpm}$ to prepare a $\mathrm{W} / \mathrm{O} / \mathrm{W}$ emulsion. The stirring was kept for $24 \mathrm{~h}$ to undergo the interfacial reaction.

After stopping the stirring, the dispersion was left for a while to break into two layers. The upper emulsion layer was separated with a separatory funnel and washed with cyclohexane, acetone, and water in turn. The oil phase was substituted by water with a rotary evaporator. Solid products were collected with centrifugation and freeze-dried. Part of the product was calcined in an air stream at $773 \mathrm{~K}$ for $1 \mathrm{~h}$.

The phases produced were identified by X-ray powder diffraction (XRD) with $\mathrm{CuK} \alpha$ irradiation and Fourier transform infrared spectroscopy (FTIR) by the potassium bromide $(\mathrm{KBr})$ pellet method. The lattice parameters $a_{0}$ and $c_{0}$ were calculated by the least squares method from diffraction angles of (002), (211), and (310) planes with mixing silicon powder as an internal standard material. For the specimen that would be identified as single phase, the crystallite size was calculated by the Scherrer equation using the diffraction data of (310) plane for $a$-axis and (002) plane for $c$-axis, and thermal gravimetry-differential thermal analysis (TG-DTA) was carried out in the range from room temperature to $1073 \mathrm{~K}$ at a temperature elevating rate of $5 \mathrm{~K} \mathrm{~min}^{-1}$. The product was dissolved in dilute $\mathrm{HNO}_{3}$, and then the calcium and phosphorus contents were measured by inductive coupled plasma atomic absorption spectroscopy (ICP) to calculate the $\mathrm{Ca} / \mathrm{P}$ ratio. The morphology was examined with a scanning electron microscope (SEM) and a transmission electron microscope (TEM).

\section{Results and discussion}

The XRD patterns of the as-prepared products are shown in Fig. 4, in which the JCPDS data of HAp (s1), ${ }^{13)}$ monetite $\left.\left(\mathrm{CaHPO}_{4}, \mathrm{~s} 2\right),{ }^{14}\right)$ and brushite $\left(\mathrm{CaHPO}_{4} 2 \mathrm{H}_{2} \mathrm{O}, \mathrm{s3}\right)^{15)}$ are also illustrated. For the specimens prepared at an initial $\mathrm{pH}$ of the inner aqueous phase of 9.0 to $12.0, \mathrm{HAp}$ is recognized as a principal product, as shown in Figs. 1 (a) to $1(\mathrm{~d})$. The diffraction lines marked with a triangle reveal the co-existence

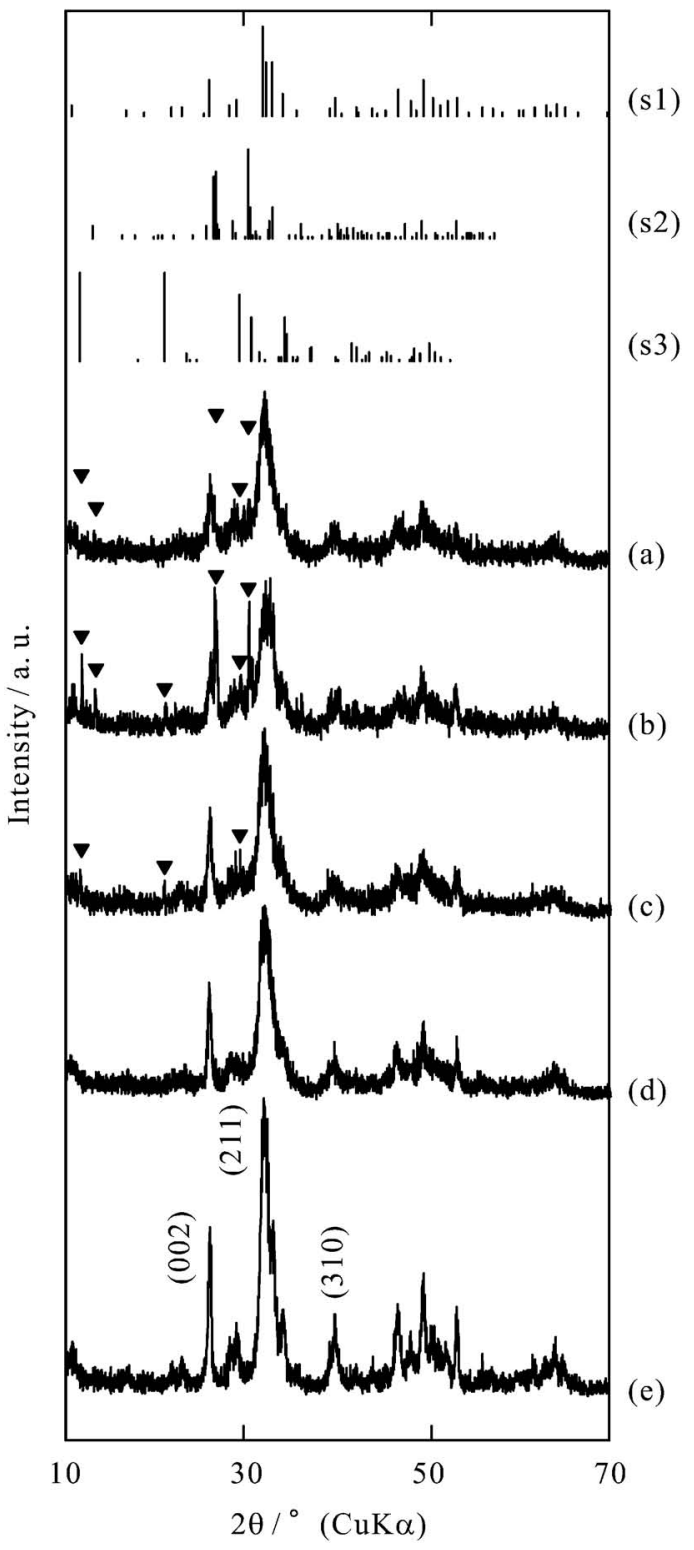

Fig. 4. XRD patterns of the as-prepared products prepared at initial pH's of (a) 9.0, (b) 10.0, (c) 11.0, and (d) 12.0; (e) prepared at an initial $\mathrm{pH}$ of 12.0 and calcined. The diffraction angle and relative intensity of (s1) HAp, (s2) monetite, and (s3) brushite data are cited from JCPDS.

of monetite and/or brushite in the specimens prepared at initial pH's of 9.0 and 10.0. The specimen prepared at an initial $\mathrm{pH}$ of 11.0 may contain a trace of them also. As seen in Fig. 2, the only HAp is produced while the $\mathrm{pH}$ in the inner aqueous phase is over 6 . After $\mathrm{pH}$ is decreased to 6 , monetite starts to be produced. Brushite should be produced by reaction of monetite with water. Even though the final $\mathrm{pH}$ reached below 6 at which monetite was a dominant solid species, HAp which had been produced before the $\mathrm{pH}$ did so can coexist. These results suggest that the dissolution rate of the HAp having been produced was slow enough and that the equilibrium has not been established.

Single phase HAp was obtained at an initial $\mathrm{pH}$ of 12.0. This means that the final $\mathrm{pH}$ was not down to 6 and left in the area of HAp.

Figure $1(\mathrm{e})$ shows the XRD pattern of the specimen pre- 


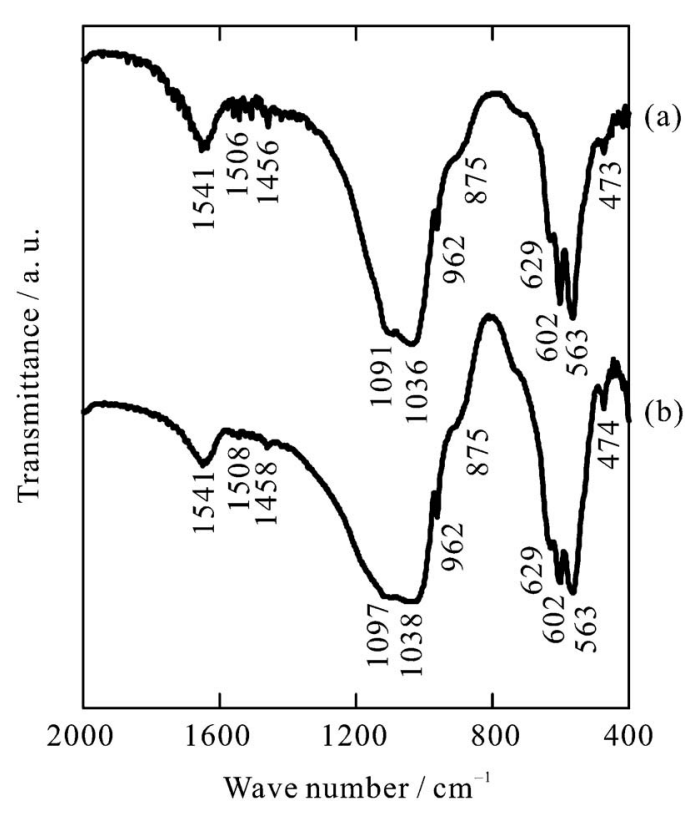

Fig. 5. FTIR spectrum of the product prepared at an initial $\mathrm{pH}$ of 12.0. (a) as-prepared, (b) calcined at $575 \mathrm{~K}$.

pared at an initial $\mathrm{pH}$ of 12.0 and calcined at $773 \mathrm{~K}$. All diffraction lines were detected at respective diffraction angles as the same as in Fig. 1(d). This proves that crystalline HAp can be produced even at $323 \mathrm{~K}$. Each diffraction line became more intense, indicating an increase just in the crystallinity.

Figure 5 shows the FTIR spectrum of the specimen prepared at an initial pH of 12.0. In Fig. 5 (a), clearly separated bands were observed at wave numbers of below $1200 \mathrm{~cm}^{-1}$. The bands at 473, 563, 602, 962, 1036, and $1091 \mathrm{~cm}^{-1}$ are assigned to $\mathrm{PO}_{4}{ }^{3-} \cdot{ }^{16)-18)}$ The band at $629 \mathrm{~cm}^{-1}$ is assigned to $\mathrm{OH}^{-} .{ }^{16), 18)}$ Therefore, this can be regarded as a typical spectrum of HAp.

$\mathrm{HPO}_{4}{ }^{2-}$ reveals infrared absorption at 872-879 and 1094 $\mathrm{cm}^{-1} \cdot{ }^{19)}$-21) The shoulder band around $875-885 \mathrm{~cm}^{-1}$ is most likely assigned to $\mathrm{HPO}_{4}{ }^{2-}$, because this is one of the dominant constituents of the inner aqueous phase. If the decomposition of $\mathrm{HPO}_{4}{ }^{2-}$ in Eq. (1) is insufficient, it will be incorporated in $\mathrm{HAp}$, for instance, as

$$
\mathrm{Ca}_{10-x}\left(\mathrm{PO}_{4}\right)_{6-x}\left(\mathrm{HPO}_{4}\right)_{x}(\mathrm{OH})_{2-x} .
$$

Carbon dioxide may possibly come into the HAp lattice from the atmosphere. B-type $\mathrm{CO}_{3}{ }^{2-}$, which is substituted for the $\mathrm{PO}_{4}{ }^{3-}$ site, reveals infrared absorption at $872,1420,1460$, and $1470 \mathrm{~cm}^{-1}{ }^{19), 22)}$ Among these, the bands at 1420 and 1470 $\mathrm{cm}^{-1}$ cannot be found. On the other hand, A-type $\mathrm{CO}_{3}{ }^{2-}$, which is substituted for the $\mathrm{OH}^{-}$site, reveals infrared absorption at 882,1500 , and $1545 \mathrm{~cm}^{-1} \cdot{ }^{19)}$,22) All of them can be recognized to exist in the spectrum. A band at 825,1382 , or $1763 \mathrm{~cm}^{-1}$ assigned to $\mathrm{NO}_{3}{ }^{-23)}$ was not detected. Thus, it is found that nitrate ion in the outer aqueous phase was not taken in the HAp lattice. A lot of finely dentate bands were observed in the range over $1300 \mathrm{~cm}^{-1}$ in Fig. 5(a). Several papers have reported that broad absorption band exists in this range. ${ }^{16)-18)}$ This is thought to be assigned to water molecules incorporated in the HAp lattice. ${ }^{18)}$

It is found that the calcination did not affect the spectrum as seen in Fig. 5(b), although the finely dentate bands below $1300 \mathrm{~cm}^{-1}$ seem to be reduced.

Figure 6 shows the TG-DTA curves of the product prepared

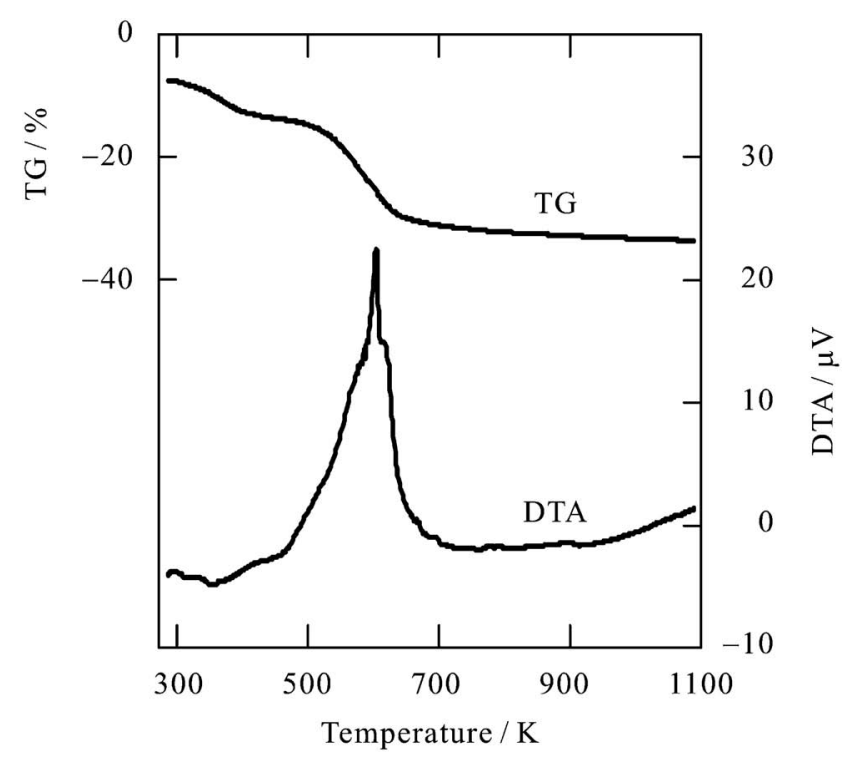

Fig. 6. TG-DTA curves of the product prepared at an initial $\mathrm{pH}$ of 12.0 .

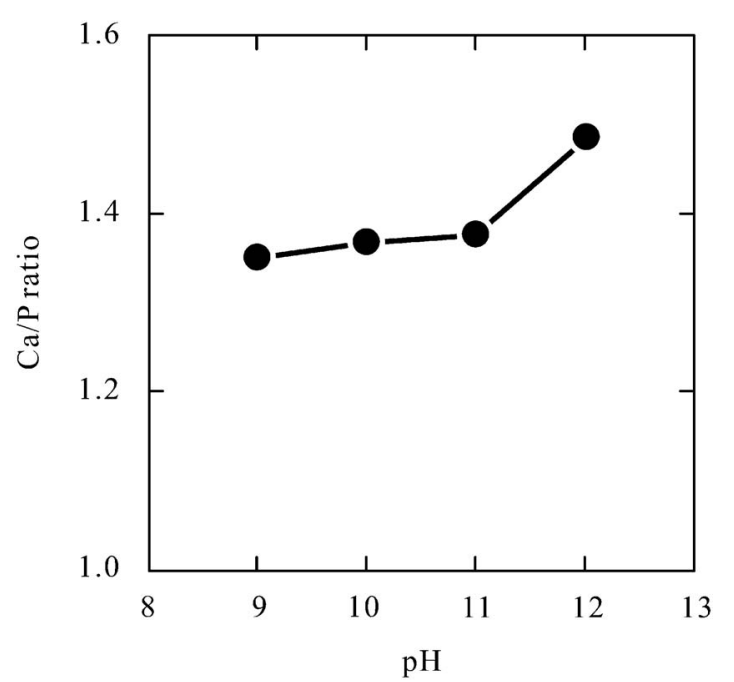

Fig. 7. Relation between the initial $\mathrm{pH}$ and the $\mathrm{Ca} / \mathrm{P}$ ratio of the product calcined.

at an initial $\mathrm{pH}$ of 12.0. A very small endothermic peak together with weight loss of $8 \%$ was observed in a temperature range of $370-420 \mathrm{~K}$. This is thought to be due to the exhalation of water. An exothermic peak together with weight loss of $20 \%$ was observed in the temperature range of 550-620 K. No change in crystalline phase was observed before and after calcination, as shown in Fig. 4. Therefore, it is thought that this change is attributed to the decomposition of Span 80 molecules adsorbed on the surface of HAp microspheres.

The change in the $\mathrm{Ca} / \mathrm{P}$ ratio with the initial $\mathrm{pH}$ is shown in Fig. 7. It was smaller than 1.4 for the specimen prepared at initial pH's of 11.0 and less, whereas the theoretical value of HAp is 1.67. These specimens may probably contain a considerable amount of monetite or brushite, for which the $\mathrm{Ca} / \mathrm{P}$ ratio is unity. Since the relative amount of them shown in Fig. 4 seems too low, it is found that they are almost amorphous. 
Even at an initial $\mathrm{pH}$ of 12.0 , the $\mathrm{Ca} / \mathrm{P}$ ratio was so small as 1.49. The incorporation of $\mathrm{HPO}_{4}{ }^{2-}$ into the $\mathrm{HAp}$ lattice has been deduced from the FTIR spectrum. While HAp is produced, the amount of $\mathrm{Ca}^{2+}$ at the reaction site is always less than the stoichiometry. Thus, it is natural to recognize that HAp produced in this system is essentially Ca-deficient. Equation (2) means that $\mathrm{Ca} / \mathrm{P}$ ratio is 1.5 at $x=1$ and that the vacancy of $\mathrm{Ca}^{2+}$ site occurs for compensating the lack of negative charge. Ca-deficient HAp is preferable to the ideal one regarding the absorption of HAp in the body.

The lattice parameters $a_{0}$ and $c_{0}$ are listed in Table 1. They are almost the same but a little larger than those of standard HAp. The expansion of HAp lattice is not inconsistent with consideration that the charge density could be reduced by the substitution of $\mathrm{HPO}_{4}{ }^{2-}$ for $\mathrm{PO}_{4}{ }^{3-}$.

The morphology of the product was not changed by calcination. Figure 8 shows the scanning electron micrographs of the products calcined. The product prepared at an initial $\mathrm{pH}$ of 12.0 was composed of microspheres of 0.5 to $2 \mu \mathrm{m}$ in diameter as shown in Fig. 8(d). This size is considered to be dependent on the size of the inner aqueous droplet. This is a principal

Table 1. Comparison of Lattice Parameters of the Specimen Prepared at an Initial $\mathrm{pH}$ of 12.0 and Calcined with the Stoichiometric HAp

\begin{tabular}{lll}
\hline \hline specimen & $a_{0} / \mathrm{nm}$ & $c_{0} / \mathrm{nm}$ \\
\hline present study & 0.9427 & 0.6897 \\
standard HAp $^{13)}$ & 0.9418 & 0.6884 \\
\hline
\end{tabular}

(a)

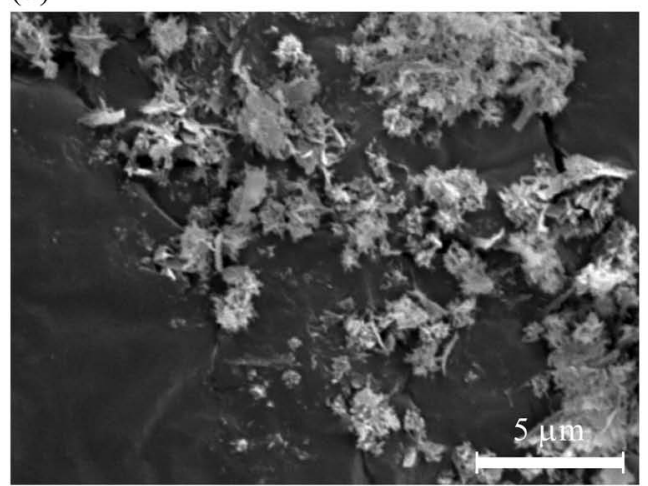

(c)

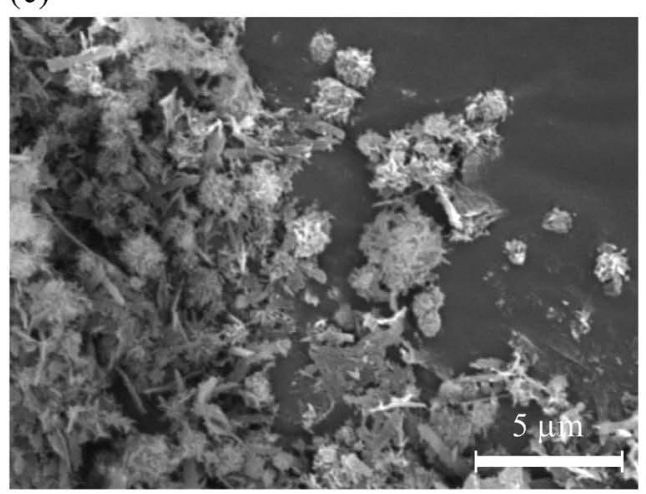

advantage of processes involving emulsion, by which the final size of the product can be controlled at preparing first emulsion. Thus, it is easily predicted that monodisperse microspheres could be obtained by monodisperse emulsifying techniques using microchannels or microporous membranes for preparing the $\mathrm{W} / \mathrm{O}$ emulsion.

The surface of the microspheres looks quite rough. A TEM micrograph shown in Fig. 9 tells the reason for it. Each microsphere is composed of acicular particles, ca. $20 \mathrm{~nm}$ in short axis and 50-200 $\mathrm{nm}$ in long axis, namely, 2.5-10 in aspect ratio. This TEM micrograph also shows that these microspheres are hollow as expected. They appear to be just assembled and weak. However, it was confirmed that they have certain strength as not to break by usual handling, calcination, or redispersion in water.

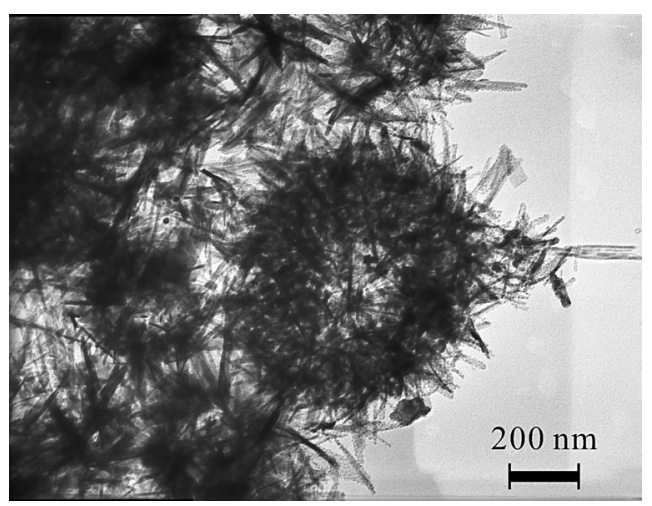

Fig. 9. Transmission electron micrograph of the product prepared at an initial $\mathrm{pH}$ of 12.0 .

(b)

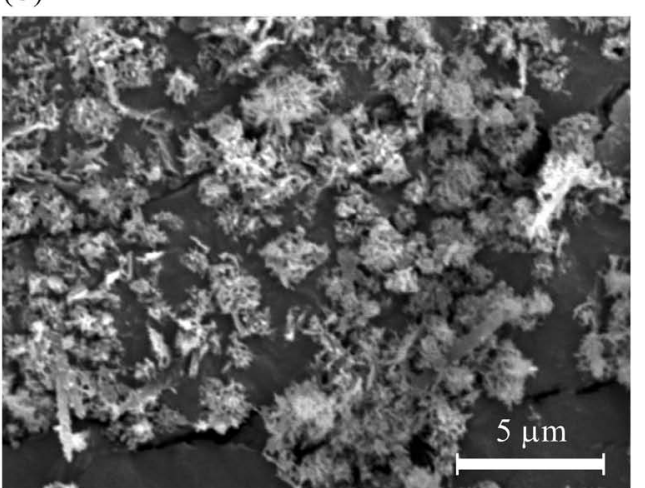

(d)

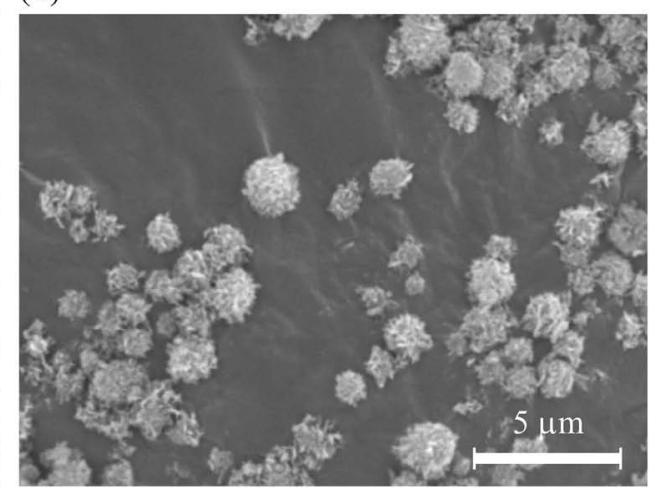

Fig. 8. Scanning electron micrographs of the products prepared at initial pH's of (a) 9.0, (b) 10.0, (c) 11.0, and (d) 12.0. 
The crystallite size was estimated by the Scherrer equation to be $22 \mathrm{~nm}$ for $a$-axis and $55 \mathrm{~nm}$ for $c$-axis. These results are almost consistent with the sizes observed on the TEM micrograph. It is expected that the HAp microspheres prepared in the present study have both chemical activity as nanoparticles and easiness for handling as microspheres.

The products prepared at an initial $\mathrm{pH}$ of 11.0 and less contain irregular particles in shape besides microspheres, as shown in Figs. 8 (a) to $8(\mathrm{c})$. These may be monetite or brushite. To obtain only microspheres, it is necessary to adopt the condition under which the only HAp is produced.

\section{Conclusions}

The interfacial reaction in a multiple emulsion was carried out. The product prepared at an initial $\mathrm{pH}$ of 12.0 was recognized as Ca-deficient HAp. The HAp microspheres were composed of nano-sized acicular particles, so that the surface was quite rough. The surface is desirable to be dense and smooth for the application to microcapsules. In order to search the optimum experimental conditions in the future, it should be useful to refer the phase diagrams drawn by thermodynamic calculation.

Acknowledgments Part of this study was financially supported by Grant-in-Aid for Scientific Research (C) No. 18560666, Japan Society for the Promotion of Science and a Grant for Promotion of Niigata University Research Projects, 2006. The authors greatly appreciate Dr. A. V. Atakan, Department of Materials Science and Engineering, Rutgers, The State University of New Jersey, for performing computations with the OLI software. We would like to acknowledge the support of Prof. M. Tanaka, Faculty of Engineering, Niigata Univeristy, for TG-DTA and FTIR analyses. We also thank Mr. N. Saito, Faculty of Engineering, Niigata Univeristy, for TEM observation, Mr. M. Oizumi, Facility for Wastewater Treatment, Niigata University, for ICP analyais, and Mr. K. Iwafune, Center for Instrumental Analysis, Niigata University, for X-ray diffraction analysis.

\section{References}

1) T. Akazawa, M. Kobayashi and K. Kodaira, Bull. Chem. Soc.
Jpn., 70, 2323-2329 (1997).

2) M. C. Sunny, P. Ramesh and H. K. Varma, J. Mater. Sci. Mater. Med., 13, 623-632 (2002).

3) C. C. Ribeiro, C. C. Barrias and M. A. Barbosa, J. Mater. Sci. Mater. Med., 17, 455-463 (2006).

4) K. Hashimoto, Y. Toda, T. Saitoh, S. Udagawa and T. Kanazawa, Inorg. Mater., 3, 30-38 (1996).

5) K. Miyata and Y. Nakahara, Prog. Organic Coating, 5, 115-129 (1977).

6) I Kimura, S. Ikarashi, N. Saito and M. Tanaka, $A d v$. Powder Technol., 8, 1-13 (1997).

7) M. Fujiwara, K. Shiokawa, Y. Tanaka and Y. Nakahara, Chem. Mater., 16, 5420-5426 (2004).

8) T. Morishige, E. Toorisaka, M. Hirata, T. Ohtake and T. Hano, J. Microencapsul., 22, 291-301 (2005).

9) R. E. Riman, W. L. Suchanek, K. Byrappa, C.-W. Chen, P. Shuk and C. S. Oakes, Solid State Ionics, 151, 393-402 (2002).

10) S.-B. Cho, J.-S. Noh, M. M. Lencka and R. E. Riman, J. Eur. Ceram Soc., 23, 2323-2335 (2003).

11) M. C. Gelabert, R. A. Laudise and R. E. Riman, J. Cryst. Growth, 197, 195-203 (1999).

12) Version 1.3. The OLI Systems, Inc.

13) JCPDS 9-432.

14) JCDPS 9-80.

15) JCDPS 9-77.

16) C. B. Baddiel and E. E. Berry, Spectrochim. Acta, 22, 1407-1416 (1966).

17) P. F. Gonzáles-Dfaz and A. Hidalgo, Spectrochim. Acta, 32A, 631-635 (1976).

18) R. Z. LeGeros et al., Scann. Microsc., 3, 129-138 (1989).

19) D. W. Holcomb and R. A. Young, Calcif. Tissue Int., 31, 189-201 (1980).

20) R. A. Young and D. W. Holcomb, Calcif. Tissue Int ., 36, 60-63 (1984).

21) A. Siddharthan, S. K. Seshadri and T. S. S. Kumar, J. Mater. Sci. Mater. Med., 15, 1279-1284 (2004).

22) M. Vignoles, G. Bonel, D. W. Holcomb and R. A. Young, Calcif. Tissue Int., 43, 33-40 (1988).

23) T. K. Anee, M. Ashok, M. Palanichamy, S. N. Kalkura, Mater. Chem. Phys., 80, 725-730 (2003). 